\title{
The cost-effectiveness of bike lanes in New York City
}

\author{
Jing Gu, Babak Mohit, Peter Alexander Muennig
}

Mailman School of Public Health, Columbia University, New York, New York, USA

\section{Correspondence to} Dr Babak Mohit, Mailman School of Public Health,

Columbia University,

722 W 168th St. Rm 480,

New York, NY 10032, USA;

bm2762@cumc.columbia.edu

Received 5 April 2016

Revised 19 July 2016

Accepted 10 August 2016
To cite: Gu J, Mohit $B$, Muennig PA. Inj Prev Published Online First: [please include Day Month Year] doi:10.1136/

injuryprev-2016-042057

\begin{abstract}
Background Our objective is to evaluate the costeffectiveness of investments in bike lanes using New York City's (NYC) fiscal year 2015 investment as a case study. We also provide a generalizable model, so that localities can estimate their return on bike lane investments.

Methods and findings We evaluate the costeffectiveness of bike lane construction using a two-stage model. Our regression analysis, to estimate the marginal addition of lane miles on the expansion in bike ridership, reveals that the 45.5 miles of bike lanes NYC constructed in 2015 at a cost of $\$ 8109511.47$ may increase the probability of riding bikes by $9.32 \%$. In the second stage, we constructed a Markov model to estimate the cost-effectiveness of bike lane construction. This model compares the status quo with the 2015 investment. We consider the reduced risk of injury and increased probability of ridership, costs associated with bike lane implementation and maintenance, and effectiveness due to physical activity and reduced pollution. We use Monte Carlo simulation and one-way sensitivity analysis to test the reliability of the base-case result. This model reveals that over the lifetime of all people in NYC, bike lane construction produces additional costs of $\$ 2.79$ and gain of 0.0022 quality-adjusted life years (QALYs) per person. This results in an incremental cost-effectiveness ratio of \$1297/QALY gained (95\% Cl - \$544/QALY gained to \$5038/QALY gained).

Conclusions We conclude that investments in bicycle lanes come with an exceptionally good value because they simultaneously address multiple public health problems. Investments in bike lanes are more cost-effective than the majority of preventive approaches used today.
\end{abstract}

\section{OBJECTIVE}

The USA has 67 million bicyclists, making over 300 million trips per year in big cities alone, ${ }^{1}$ with almost 700 deaths and 48000 serious injuries per year. ${ }^{2}$ This high level of casualties makes the USA the most dangerous place among wealthy nations to bicycle. Per kilometre and per trip cycled, US bicyclists are twice as likely to be killed as German cyclists and over three times as likely as Dutch cyclists. ${ }^{3}$ One effective and intuitive way of preventing injury is to introduce bike lanes on all major cycling routes, an infrastructure intervention that reduces all forms of injury by $25 \% .{ }^{4}$ Unlike helmet laws, bike lanes do not require behavioural change on the part of the cyclist, and they come with other benefits. For example, they 'normalise' exercise behaviours, reduce pollution and may help address the obesity epidemic in the USA. In places where bike lanes have been installed, cycling (and possibly other forms of exercise) tends to increase greatly. This creates a virtuous cycle, as the more people who bike, the safer it becomes to cycle. ${ }^{5}$

Well-designed bike lanes improve safety for people on bikes and reduce excessive speeding in cars, organise traffic flow and protect pedestrians. Bike lanes take three forms. 'Class I' bike lanes provide a route that is physically separated from moving traffic. 'Class II' bike lanes have a marked lane on the road. Finally, 'Class III' bike lanes merely provide shared road markings for drivers and add safety legislation. Each of these comes with a different set of risks and benefits. For example, Class II bike lanes often force cyclists to ride next to parked cars and place the cyclist at risk of colliding with suddenly opened car doors. Nevertheless, much of the academic literature on bike lanes treats all forms of bike lanes equally.

Our objective is to evaluate the more generic notion of a 'bike lane' investment using New York City's (NYC) 2015 investment as a case study. We use NYC because it provides a known investment in bicycle infrastructure. We use predicted 2015 values (rather than actual values) so that year-to-year variations in weather, road conditions or other factors are smoothed across many years. While we use NYC as an example, our intent is to provide a much more generalisable model, such that localities can estimate the return on their investment in bike paths. We undertake this study because, while investments in bike lanes appear to broadly benefit health, it is not clear that they bring more value than other types of health investments that a city or locality might make, such as expansion of healthcare services.

\section{DESIGN}

We evaluated the cost-effectiveness of the construction of bike lanes in NYC in 2015 as a case study. We first used regression analysis to estimate miles of bike lanes constructed in 2015 and to model the effect of additional lane miles on the expansion in bike ridership. Using data through 2014, we use ordinary least squares (OLS) to predict values for 2015 so that analyses are not influenced by temporary change in the weather or road conditions that might influence bike path construction, ridership or injury. We then constructed a Markov model using TreeAge Software (TreeAge Software. TreeAge Pro 2015 (R 1.0). Williamstown, Massachusetts: TreeAge Software; available at https://www.treeage.com, 2015) to estimate the costs and effectiveness of bike lane construction in 2015 for people starting to ride bikes at the age of 36 (the average age of people riding within NYC) over the next 34 years. While we use NYC as an example, we also rely on broader sources of data so that the model outputs are more generalisable. 


\section{Original article}

\section{Participants}

The Markov model (displayed in figure 1) targets the entire cohort of 8.5 million people who live in NYC in $2015,{ }^{6}$ including bike riders (both existing and new riders because of added bike lanes) and non-riders. The model has two major arms, namely the status quo arm, which simulates the situation without bike lane construction in 2015, and the bike lane arm, which simulates the situation after the construction of bike lanes in 2015. The latter arm is depicted in figure 1, and given the structural similarity of the two arms, the status quo arm has been collapsed. Both arms include the whole NYC population. Under both the status quo arm and the bike lane arm, a portion of NYC population chooses biking as their main way of transportation, while the others do not. Subsequently, both bike riders and non-riders have a probability of injury that is different from one another.

We estimate that with a population of 8.5 million people and a ridership probability of $0.013,{ }^{7}$ the number of bike riders in the status quo arm is 110500 persons. With a $9.32 \%$ increase, ${ }^{8}$ we estimate that there will be 120445 riders in the intervention arm.

\section{Regression analysis}

We obtained the number of bike lane miles constructed from 2007 to 2014 from the NYC Department of Transportation (NYC DOT). ${ }^{9}$ Using these data, we estimated that the NYC DOT constructed 45.5 miles of bike lanes in 2015 at a cost of $\$ 8109$ 511. NYC DOT also tracks trends in NYC cycling using the In-Season Cycling Indicator, which is derived from counts of bicycle traffic at several locations. ${ }^{8}$

We ran a simple linear regression model with the percentage of increase in ridership as the independent variable and the additional bike lane miles constructed every year as the dependent variable from 2007 to 2014. The percentage of increase in ridership was calculated using the in-season cycling indicator of each year. The estimated model is $\mathrm{Y}=0.004 \mathrm{X}-0.0888$, with $\mathrm{R}^{2}$ equals to 0.59 , which indicates that the model is able to explain the variance of the dependent variable quite well.

This OLS analysis revealed that the percentage of expansion in bike ridership would increase by $0.4 \%$ for every additional one mile of bike lane construction. Using the fitted equation, we calculated that the probability of riding bikes would increase by $9.32 \%$ if 45.5 lane miles were constructed in 2015 .

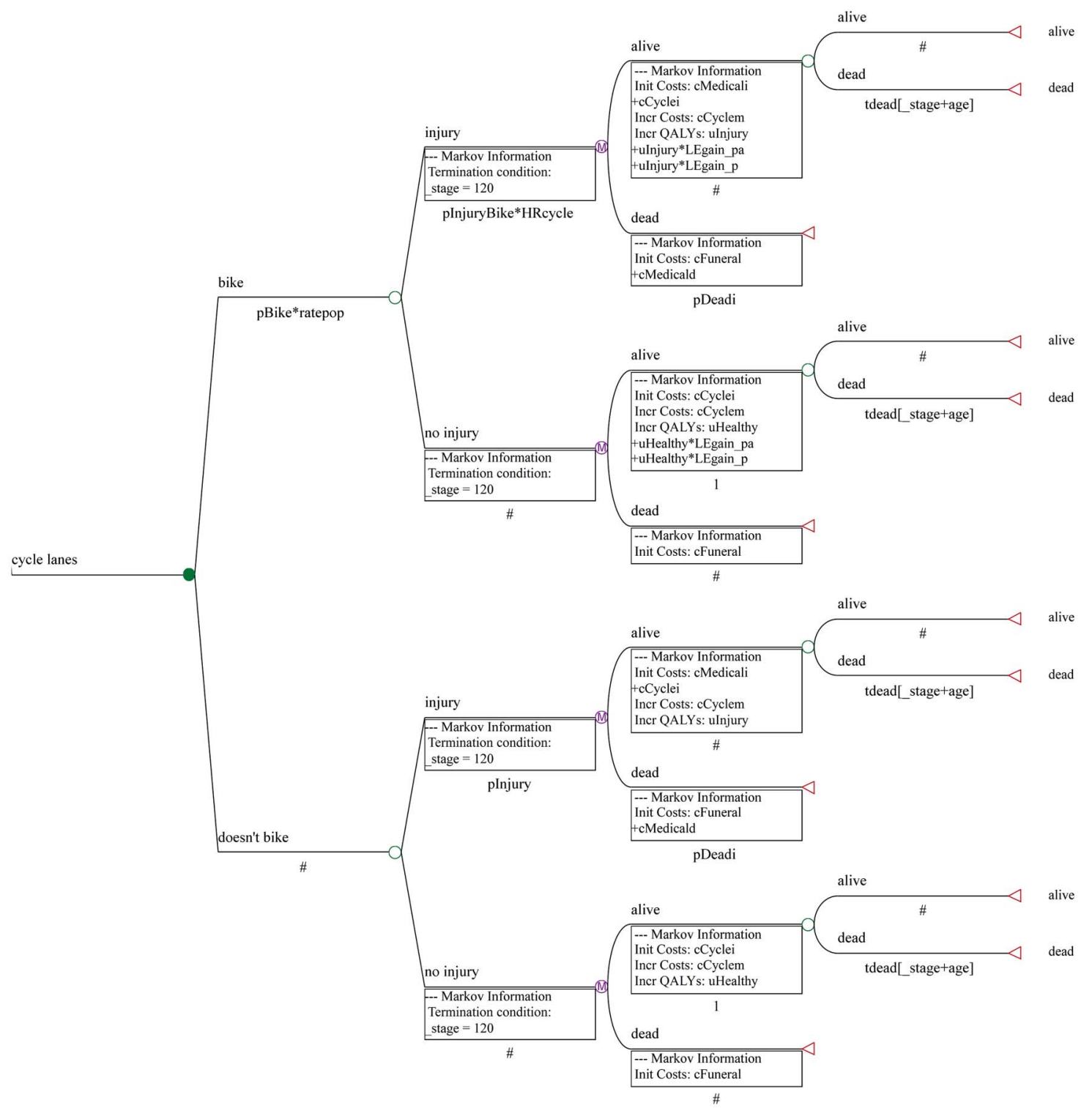

Figure 1 Markov model of bike lane implementation in New York City (NYC). 
Table 1 Values used in the Markov model evaluating bike lane construction in 2015 versus the status quo

\begin{tabular}{|c|c|c|c|c|c|c|}
\hline Variables & $\begin{array}{l}\text { Abbreviation } \\
\text { in tree diagram }\end{array}$ & Base & SD & Low & High & Data sources \\
\hline \multicolumn{7}{|l|}{ Lifetime medical costs per capita (\$) } \\
\hline Fatal injury & cMedicald & 11973 & 5000 & & & $\mathrm{CDC}^{10}$ \\
\hline Non-fatal injury & cMedicali & 57764 & & 53210 & 136067 & \\
\hline Death costs per capita (\$) & cFuneral & 7306 & 5000 & & & National Funeral Directors Association ${ }^{11}$ \\
\hline \multicolumn{7}{|l|}{ Programme costs total/per capita (\$) } \\
\hline Implementation & & $8109511 / 0.97$ & 0.77 & & & Elvik et al.; $;^{13}$ Bushell et al.; ${ }^{12}$ Litman; $^{14}$ Zegeer $^{15}$ \\
\hline Maintenance per year & & $532971 / 0.06$ & 0.06 & & & \\
\hline \multicolumn{7}{|l|}{ Probability of injury } \\
\hline Non-riders & plnjury & 0.0004 & & 0 & 0.0008 & NYS DMV; ${ }^{18}$ NYS DOH ${ }^{19}$ \\
\hline Bike riders & plnjuryBike & 0.0008 & 0.0003 & & & $\mathrm{CDC}_{i}^{10}$ Statista $^{7}$ \\
\hline Case fatality ratio & pDeadi & 0.08 & & 0 & 0.15 & NYS DMV ${ }^{18}$ \\
\hline Probability of riding bikes, status quo & pBike & 0.013 & 0.003 & & & ACS, 2009-2013 \\
\hline Increase in bike ridership, Vision Zero (\%) & & 9.32 & 1 & & & NYC DOT (2015b) \\
\hline$H R$, injury, Vision Zero & HRcycle & 0.83 & 0.1 & & & NYC DOT (2015c); Elvik et al ${ }^{13}$ \\
\hline$H R Q L$, injured & ulnjury & 0.55 & & & & EQ5D survey \\
\hline Average age (years) & & 36 & 10 & & & New York City Department of City Planning, 2012 \\
\hline \multicolumn{7}{|l|}{ LE gain, Vision Zero (years) } \\
\hline From physical activity & LEgain_pa & 0.033 & & 0 & 0.04 & Rabl and De Nazelle ${ }^{17}$ \\
\hline From reduced pollution & LEgain_p & 0.047 & & 0 & 0.05 & Rabl and De Nazelle ${ }^{17}$ \\
\hline
\end{tabular}

\section{Costs}

We adjusted monetary costs to constant 2015 US\$ using the general consumer price index as listed in table 1 . We went on to obtain lifetime medical costs for non-fatal, hospitalised and fatal injuries per person from the 2010 US averages using the CDC's Web-based Injury Statistics Query and Reporting System (CDC WISQARS). ${ }^{10}$ We also derived costs per person associated with death (funeral) from the 2009 National Funeral Director's survey. ${ }^{11}$ We included the cost of death (burial costs) in the model, even though the entire cohort will eventually expire over time, and thus the monetary cost of death is the same over a lifetime, regardless of whether the cost of death is calculated at an earlier or later point in life. The rationale for including these costs in our calculations is that bike lanes have the potential to reduce premature deaths, allowing members of the population to die of other causes in the later stages of life. Because of this, the time course over which the death costs are discounted is longer in the speed-reduction branch and shorter in the nonintervention branch. This difference in the time of discounting leads to monetary differences significant enough to include in the model.

We obtained implementation cost and maintenance cost per mile of bike lanes through a review of the literature and reports. ${ }^{12-15}$ We then multiplied the cost per mile by estimated lane miles constructed in 2015, which we had derived from the previous regression analysis.

We derived the literature sources for model input parameters of cost, quality-adjusted life years (QALY), probabilities and others through multiple keyword searches, related to the burden of injury of bicycle rider studies, on Google Scholar, Web of Science and PubMed. After sources were selected, they were ranked according to levels of evidence.

\section{Quality-adjusted life years}

We assessed the impact of injury and death on victim's health-related quality of life (HRQL) using the EuroQol 5D (EQ5D-5L). HRQL is required to calculate QALYs, and effectively adjusts a year of life lived with a condition for health. HRQL is scaled from 0 to 1 , with 0 representing death and 1 representing a state of perfect health. Our objective was to obtain a score that represented an injury that was serious enough to require hospital admission. We assumed that other injuries would only incur a transient decrease in HRQL and would therefore not incur a meaningful change in HRQL over the victim's life course.

The EQ5D captures the following five domains of health: mobility, anxiety/depression, self-care, usual activities and pain/ discomfort. We used an earlier estimate of the HRQL score of a person who incurred an injury serious enough to be hospitalised. This score was obtained from two paediatric orthopaedic surgeons at Columbia University Medical Centre who had extensive experience following such individuals over the course of their lives. ${ }^{16}$ We used the average value of their predicted EQ5D score, 0.55 , in our model for injury victims who required hospitalisation.

We followed the logic from Rabl and De Nazelle ${ }^{17}$ to estimate the additional gains in life expectancy (LE) due to increased physical activity (PA) and reduced pollution. The LE gain due to PA from 25 to 65 years old is 1.32 years. Thus, the LE gain from PA per year is 0.033 .

For air pollution, the dose-response function for mortality due to chronic PM2.5 exposure is linear and with slope: $\mathrm{sDR}=0.00065$ years of life lost per person per year per $\mu \mathrm{g} / \mathrm{m}^{3}$ of PM2.5. Also the researchers estimated that avoided emissions due to shift to bicycling is $71.8 \mathrm{~g}$ PM2.5/year. Thus, the 


\section{Original article}

LE gain due to reduced pollution is 0.04667 QALYs. Besides the QALYs gained from reduced injury, additional gain in LE due to increased PA and changes in air pollution were also taken into account using estimate obtained from the health literature. New bike riders gain an average of 0.033 QALYs per year from increased exercise and New Yorkers as a whole gain 0.047 QALYs per year from reduced exposure to pollution.

\section{Probabilities}

Probabilities and related inputs are listed in table 1. We obtained the number of people seriously injured and killed from traffic crashes in 2013 from New York State Department of Motor Vehicles. ${ }^{18}$ We used these numbers and the population in NYC to calculate the probability of injury and the case fatality ratio for both bike riders and non-riders. ${ }^{19}$

Bike riders have a higher probability of injury than those who use other forms of transportation. The number of traffic injuries of cyclists in the USA was first derived from CDC WISQARS. ${ }^{10}$ Dividing the number of injuries by the total estimated number of cyclists in the USA, ${ }^{7}$ we obtained the probability of getting all levels of injuries for cyclists. A ratio of serious injuries to all levels of injuries was then calculated using the numbers of injured cyclists and treated and released cyclists. ${ }^{10}$ We then calculated the probability of serious injury for cyclists by multiplying the probability of all injuries and the ratio of serious injury. The HR injury when new bike lanes were constructed compared with the status quo (before 45.5 miles of bike lane were added) was obtained from a comprehensive review of the literature. ${ }^{13} 20$ All outcomes in the model were adjusted to 2015 constant US\$ and discounted at a rate of $3 \%$ per year. ${ }^{21}$

\section{Markov model}

Our Markov model is based on a societal perspective and, as we depict in figure 1, has two competing alternatives: adding bike lanes or the status quo. Both the bike lane arm and the status quo arm are the same except that the bike lane arm has an increased probability of riding bikes, a reduced risk of injury for bike riders, costs associated with bike lane implementation and maintenance and additional effectiveness because of PA and reduced pollution.

Irrespective of the arm of the model, a bike rider has a small risk of serious injury from traffic incidents and a significant

Table 2 Assumptions used in the Markov model evaluating bike lane construction in 2015 versus status quo

\begin{tabular}{ll}
\hline Assumption & Rationale (impact on estimates) \\
\hline $\begin{array}{l}\text { Future lost productivity and leisure } \\
\text { time costs of injury are included } \\
\text { within the health-related quality-of-life } \\
\text { score }\end{array}$ & $\begin{array}{l}\text { EQ5D scores may implicitly include lost } \\
\text { productivity and leisure time, however } \\
\text { this has been debated (favours status } \\
\text { quo) }\end{array}$ \\
$\begin{array}{l}\text { Benefits of bike lane construction are } \\
\text { limited to bike riders }\end{array}$ & $\begin{array}{l}\text { Construction of bike lanes may also } \\
\text { reduce injury risks for car drivers and } \\
\text { pedestrians (favours status quo) }\end{array}$ \\
$\begin{array}{l}\text { The trend of bike lane construction } \\
\text { during the past 7 years will continue }\end{array}$ & $\begin{array}{l}\text { Bike lane construction may be more } \\
\text { emphasised because a citywide traffic } \\
\text { in 2015 }\end{array}$ \\
$\begin{array}{l}\text { safety programme initiated in 2014. } \\
\text { (favours bike lane construction) }\end{array}$ \\
$\begin{array}{l}\text { Injury victims may be at higher risk of } \\
\text { future death both from physical }\end{array}$ \\
occurs only at the time of injury & $\begin{array}{l}\text { limitations and economic impact of the } \\
\text { injury on the victim's life (favours } \\
\text { status quo) }\end{array}$ \\
\hline
\end{tabular}

Table 3 Costs and quality-adjusted life years (QALYs) of bike lane construction in 2015 versus status quo

\begin{tabular}{lcl}
\hline & Point estimate & $95 \% \mathrm{Cl}$ \\
\hline Costs, status quo & 31.28 & (7.04 to 65.05$)$ \\
Costs, bike lanes & 34.07 & $(9.61$ to 67.78$)$ \\
Incremental costs & 2.79 & $(-1.11$ to 6.57$)$ \\
QALYs, status quo & 31.076 & $(24.8878$ to 32.4646$)$ \\
QALYs, bike lanes & 31.0782 & (24.8898 to 32.4673$)$ \\
Incremental QALYs & 0.0022 & $(0.0008$ to 0.0038$)$ \\
ICER & 1296.5 & $(-544.08$ to 5037.89$)$ \\
\hline
\end{tabular}

ICER, incremental cost-effectiveness ratio.

chance of remaining healthy. Under the injury and non-injury arms of both the status quo and bike lane alternatives, we developed a two-state Markov process such that every subject is exposed to an annual, age-specific risk of death. ${ }^{22}$ Survivors will gain one HRQL-adjusted life year from age 36 to age 70 years, reflecting the average age of cyclists in the city. If the rider remains healthy, we assigned no costs except the one-time implementation costs and annual maintenance costs of bike lanes in the bike lane alternative arm of the model. If the rider is injured, we assigned an annual medical cost associated with a serious injury and a decrement in HRQL over the average remaining LE of the injured cyclist. Uninjured bicyclists gain both HRQL and LE because of increased PA and reduced pollution. The underlying assumptions of the modelling approach are listed in table 2 .

We used Monte Carlo simulation and one-way sensitivity analysis to test the reliability of the base-case result. We either included what we recognised as plausible boundaries for the values or included the known random error associated with an estimate in the Monte Carlo simulation. We also employed halfcycle corrections to adjust for related modelling uncertainties.

\section{RESULTS}

\section{Cost-effectiveness of bike lanes}

As shown in table 3, for all people in NYC, bike lane construction as a part of Vision Zero produced an additional cost of $\$ 2.79$ per person and an incremental gain of 0.0022 QALYs over their lifetimes, compared with the status quo. The incremental cost-effectiveness ratio (ICER) was \$1297/QALY gained (95\% CI - \$544/QALY gained to \$5038/QALY gained).

\section{Sensitivity analysis}

An influence analysis ('tornado' diagram) suggested that the most important variable in the analysis was the probability of injury. One-way sensitivity analysis showed that the value of ICER would drop as the probability of getting injury increased. However, the maximum value of the ICER was $\$ 1318 /$ QALY gained when the probability of injury was 0 . Thus, our conclusion that the programme was highly favourable was robust to a wide variation in injury estimates based on exercise and pollution impacts alone.

\section{CONCLUSION}

Bicycle lanes address multiple public health problems simultaneously. They reduce injury and death, they promote exercise, and they reduce pollution. We explored the cost-effectiveness of 1 year of investment in bike lanes in NYC as a case study. We do so after considering costs and health effects of the investment on New Yorkers and account for long-term benefits as well as maintenance costs of the lanes installed in the built 
environment. In NYC, the investment comes in at an exceptionally good value, costing just \$1297/QALY gained for the 2015 investment cycle. This is far more cost-effective than preventive approaches in medicine that few would argue should not be implemented. For instance, screening and treatment for HIV/ AIDS in high-risk populations cost $\$ 50$ 000/QALY gainednearly 40 times as much. ${ }^{23}$ It is also considerably more costeffective than either providing private health insurance or expanding Medicaid. ${ }^{16}{ }^{24}$

Our study was subject to a number of important limitations. Foremost, there are few causal estimates of the effects of bike lanes on safety or, particularly, usage. ${ }^{25}$ While studies consistently show that bike lane construction is followed by increased cycling and reduced injury, these 'outcomes' might simply reflect national trends towards an increased interest in cycling. We managed this uncertainty by conducting broad sensitivity analyses on model inputs.

Our model also uses generic references for potentially important effects of bike lanes. Some of our references accounted for the lifelong impacts of injuries, reduced exposure to pollution and increased exercise afforded to the cyclist. However, they measure average effects for an average individual living in an average city. ${ }^{17}$ Yet, this only provides a snapshot of the impact of a city's investment in bike paths. As cycling grows more popular, it becomes safer to cycle. The resulting increase in cyclists may generate momentum for cycling or a change in political resistance to (or acceptance of) cyclists. Some cities (eg, Portland, OR and Washington, DC) have been able to tolerate a greater than $400 \%$ increase in cyclists over the past two decades with relatively little political resistance. Others, such as NYC, have seen the emergence of anticycling groups as bike lanes and cyclists have proliferated. To fully understand this relationship, it would be helpful to have a complex systems dynamics model that could be tailored to different urban contexts.

As the USA moves to invest more in non-medical policies in the name of health prevention under the Affordable Care Act, policymakers and payers are too often left wondering where their investments might produce good value. Bike lanes are one investment that certainly seems to fit the bill.

\section{What is already known on the subject?}

- The USA has 67 million bicyclists, making over 300 million trips per year in big cities alone with 700 deaths and 48000 serious injuries per year which makes the USA the most dangerous place among wealthy nations to bicycle.

- Bike lanes reduce all forms of injury by $25 \%$.

\section{What this study adds?}

- We demonstrate that the incremental cost-effectiveness ratio of bike lanes is $\$ 1297 /$ quality-adjusted life years (QALY) gained (95\% Cl - \$544/QALY gained to \$5038/QALY gained).

- Our study considers multiple factors to highlight the need for further investment in bike lanes as a crucial part of urban infrastructure improvement.
Contributors JG and BM cooperated in the analysis and writing of this paper. PAM supervised the analysis and cooperated in the writing and edited the final draft.

Funding This research was supported by Grant 1 R49 CE002096 from the National Center for Injury Prevention and Control of the CDC to the Center for Injury Epidemiology and Prevention at Columbia University Medical Center.

Disclaimer The contents of the manuscript are the sole responsibility of the authors and do not necessarily reflect the official views of the funding agency.

Competing interests None declared.

Provenance and peer review Not commissioned; externally peer reviewed.

\section{REFERENCES}

1 The League of American Bicyclists. Where We Ride 2014-Analysis of Bike Commuting. Secondary Where We Ride 2014_Analysis of Bike Commuting 2015. http://www.bikeleague.org/sites/default/files/Where_We_Ride_2014_data_web.pdf

2 National Highway Traffic Safety Administration. Traffic Safety Fact 2011 Data. Secondary Traffic Safety Fact 2011 Data 2011. https://crashstats.nhtsa.dot.gov/Api/ Public/ViewPublication/811753

3 Pucher J, Dijkstra L. Promoting safe walking and cycling to improve public health: lessons from the Netherlands and Germany. Am J Public Health 2003;93:1509-16.

4 Lusk AC, Furth PG, Morency P, et al. Risk of injury for bicycling on cycle tracks versus in the street. Inj Prev 2011;17:131-5.

5 New York City Department of Transportation. Vision Zero One Year Report. Secondary Vision Zero One Year Report 2015. http://www.nyc.gov/html/visionzero/ assets/downloads/pdf/vision-zero-1-year-report.pdf

6 US Census Bureau. QuickFacts: New York city, New York. Secondary QuickFacts: New York city, New York 2016. https://www.census.gov/quickfacts/table/ PST045215/3651000

7 Statista. Number of Cyclists/Bike Riders in the USA, 2015. Secondary Number of Cyclists/Bike Riders in the USA, 2015 2016. http://www.statista.com/statistics/ 227415/number-of-cyclists-and-bike-riders-usa/

8 New York City Department of Transportation. 2014 NYC In-Season Cycling Indicator —An Estimate of Trends in Regular Cycling for Transportation. Secondary 2014 NYC In-Season Cycling Indicator-An Estimate of Trends in Regular Cycling for Transportation 2015. http://www.nyc.gov/htm//dot/downloads/pdf/2014-isci.pdf

9 New York City Department of Transportation. Bicycle Projects by Borough and Type, from 2006 to 2014. Secondary Bicycle Projects by Borough and Type, from 2006 to 2014. 2015. http://www.nyc.gov/htm//dot/downloads/pdf/bikeroutedetailscy06-cy14.pdf

10 Centers for Disease Control and Prevention. Web-based Injury Statistics Query and Reporting System (WISQARS). National Center for Injury Prevention and Control, Centers for Disease Control and Prevention, 2003.

11 National Funeral Directors Association. 2009 National Funeral Directors' Survey. Secondary 2009 National Funeral Directors' Survey 2009. http://nfda.org/ about-funeral-service-/trends-and-statistics.html

12 Bushell MA, Poole BW, Zegeer CV, et al. Costs for pedestrian and bicyclist infrastructure improvements. University of North Carolina Highway Safety Research Center, University of North Carolina, Chapel Hill 2013:45.

13 Elvik $\mathrm{R}$, Vaa T, Erke $\mathrm{A}$, et al. The handbook of road safety measures. Bingley, UK: Emerald Group Publishing, 2009.

14 Litman T. Traffic calming: benefits, costs and equity impacts. Victoria, BC, Canada: Victoria Transport Policy Institute, 1999.

15 Zegeer CV. Pedestrian facilities users guide providing safety and mobility. Diane Publishing, 2002.

16 Muennig PA, Epstein M, Li G, et al. The cost-effectiveness of New York City's safe routes to school program. Am J Public Health 2014;104:1294-9.

17 Rabl A, De Nazelle A. Benefits of shift from car to active transport. Transport Policy 2012;19:121-31

18 New York State Department of Motor Vehicles. Summary of New York City Motor Vehicle Crashes. Secondary Summary of New York City Motor Vehicle Crashes 2013. http://dmv.ny.gov/statistic/2013nyc.pdf

19 New York State Department of Health. Vital Statistics of New York State 2013, Table 1. Secondary Vital Statistics of New York State 2013, Table 1 2013. https:/l www.health.ny.gov/statistics/vital_statistics/2013/table01.htm

20 New York City Department of Transportation. Manhattan Pedestrian Safety Action Plan. Secondary Manhattan Pedestrian Safety Action Plan 2015. http://www.nyc. gov/html/dot/downloads/pdf/ped-safety-action-plan-manhattan.pdf

21 Weinstein MC, Siegel JE, Gold MR, et al. Recommendations of the panel on cost-effectiveness in health and medicine. JAMA 1996;276:1253-8.

22 Arias E. United States Life Tables, 2010, Table 1. National Vital Statistics Reports. Centers for Disease Control and Prevention, 2014:1-132.

23 Paltiel AD, Weinstein MC, Kimmel AD, et al. Expanded screening for HIV in the United States--an analysis of cost-effectiveness. N Engl J Med 2005;352:586-95

24 Muennig P, Franks P, Gold M. The cost effectiveness of health insurance. Am J Prev Med 2005;28:59-64.

25 Chen L, Chen C, Srinivasan R, et al. Evaluating the safety effects of bicycle lanes in New York City. Am J Public Health 2012;102:1120-7. 


\section{The cost-effectiveness of bike lanes in New York City}

Jing Gu, Babak Mohit and Peter Alexander Muennig

Inj Prev published online September 9, 2016

Updated information and services can be found at:

http://injuryprevention.bmj.com/content/early/2016/09/09/injuryprev2016-042057

\section{These include:}

References This article cites 8 articles, 1 of which you can access for free at: http://injuryprevention.bmj.com/content/early/2016/09/09/injuryprev2016-042057\#BIBL

Email alerting Receive free email alerts when new articles cite this article. Sign up in the service box at the top right corner of the online article.

\section{Notes}

To request permissions go to:

http://group.bmj.com/group/rights-licensing/permissions

To order reprints go to:

http://journals.bmj.com/cgi/reprintform

To subscribe to BMJ go to:

http://group.bmj.com/subscribe/ 